\title{
The National SAFE KIDS Campaign (USA)
}

\author{
Angela Mickalide
}

The National SAFE KIDS Campaign is the first and only nationwide childhood injury prevention program in the United States focusing on preventing unintentional injuries to children ages 14 and under. Herta Feely, a public relations and media consultant, and Martin Eichelberger, MD, Director of Trauma Services at Children's National Medical Center, cofounded the Campaign in 1987. Ms Feely served as the National SAFE KIDS Campaign Executive Director until 1993 and is now a member of its Technical Advisory Board. Dr Eichelberger has served as President since the Campaign's inception. Heather Paul, $\mathrm{PhD}$, highly experienced in strategic planning and non-profit health management, took the reins as the campaign's second Executive Director in 1994.

The 30 members of the national staff provide technical assistance to more than 180 state and local SAFE KIDS coalitions. Programmatic guidance is given by the 13 members of the Technical Advisory Board who hail from federal agencies, academia, grassroots coalitions, and clinical practice. In addition, the Campaign heads the National Coalition to Prevent Childhood Injuries, 80 national health, safety, and educational organizations interested in childhood injury prevention. Former US Surgeon General C Everett Koop, MD, is the campaign's Chairman, and Vice President $\mathrm{Al}$ Gore and Tipper Gore are Honorary Chairs.

\section{Staff}

The national office staff serves the state and local coalitions by: facilitating their development and maintenance, initiating public policy advocacy; coordinating outreach to national and local media; securing financial donations and product discounts for the coalitions; providing technical assistance and training conferences for coalition leaders; fostering information sharing through several publications, including Campaign Update and Public Policy Watch; and researching and developing targeted injury prevention programs and support materials.

The Executive Director, Heather Paul, PhD, oversees all operations of the Campaign with special attention to strategic planning and development. Kathryn Kincaid, MA, Associate Director and Communications Director, is responsible for assisting the Executive Director in the management of the Campaign, and oversees the development and production of internal/external publications and promotional materials, and coordinates national and local media outreach. Angela Mickalide, PhD, Program Director, conducts the Campaign's research and evaluation activities and is responsible for the development of injury fact sheets and the maintenance of the resource library. Jeffrey Diver, National Field Director, is responsible for all technical assistance and communications with the Campaign's state and local SAFE KIDS coalitions. Jan Kaplan, MSPH, Public Policy Director, handles all Campaign activities related to public policy, including federal, state, and local legislative and regulatory oversight.

\section{Funding}

Johnson \& Johnson is the Campaign's founding sponsor and has provided core support to the National SAFE KIDS Campaign for the past eight years. Additional funding is provided by the private sector (for example, Bell Sports, Inc, BRK/First Alert, Delta and Peerless Faucet Companies, the Gas Appliance Manufacturers Association) as well as the federal government (for example, US Fire Administration, Maternal and Child Health Bureau, National Highway Traffic Safety Administration). The Campaign also generates operating revenue from material sales (for example, brochures, videos, injury prevention programs, resource guides) and consultation with selected manufacturers and publishers.

\section{Philosophy and goals}

The motto of the Campaign is 'SAFE KIDS are no accident! @'. Recognizing that unintentional injuries are both predictable and preventable, the Campaign targets its efforts to low income and minority children who are at greatest risk. Special emphasis is placed on developing culturally relevant and linguistically appropriate materials, and on working with Campaign sponsors to make safety products (for example, bicycle helmets, child safety seats, smoke detectors) available to families who otherwise could not afford them.

The National SAFE KIDS Campaign addresses several major unintentional injury risks to children: traffic injuries (passenger, pedestrian, and bicycle); fire and burns; drownings; poisonings; chokings; and falls. The Campaign's long term goals are to:

- Raise awareness among adults, especially parents and caregivers, that injuries are the leading health threat facing children today;

- Build long-term grassroots coalitions to implement childhood injury prevention prog- 
rams in states and communities nationwide;

- Stimulate changes in environments, products, laws, and behaviors that will prevent injuries to children;

- Make childhood injury a public policy priority for federal, state, and local policymakers, and pass laws that directly affect the safety of children such as bike helmet legislation, child restraint laws, and smoke detector regulations; and

- Focus attention on, and designing injury prevention strategies for, children of lowincome families.

\section{State and local SAFE KIDS coalitions}

The more than 180 state and local SAFE KIDS coalitions at the heart of the Campaign share the common goal of making homes, schools, and communities safer for children. Each coalition is run by a lead organization (for example, hospital, health department) that has signed an agreement to build and sustain a strong injury prevention presence in the state or community. Each coalition is supported by a cross section of community leaders such as public health officials, healthcare workers, firefighters, teachers, law enforcement officers, business professionals, and concerned parents. All year long, coalition activities encompass public education, community programming, safety product distribution, legislation, media outreach, and program evaluation.

\section{Approach}

The Campaign has developed and implemented four targeted injury prevention programs: SAFE KIDS CYCLE SMART: A Bicycle Safety Program; the Scald Burn Prevention Strategy; PROJECT GET ALARMED: A Residential Fire Detection Strategy; and SAFE KIDS BUCKLE UP: A Child Occupant Protection Strategy. These strategies are comprehensive, step-by-step guides to conducting multifaceted childhood injury prevention programs in communities. Each injury prevention strategy is intended to give volunteers the necessary tools to forge progress in the 'Es' of injury control: education; engineering/environmental change; enactment/enforcement; and evaluation.

A good example of this multifaceted approach is illustrated by PROJECT GET ALARMED. Each year in the United States, approximately 1000 children ages 14 and under die in residential fires. More than 10 times as many-about 11400 -are seriously injured. Approximately $65 \%$ of the children who die are 4 years old or younger. To address these alarming statistics, the Campaign launched this strategy in October 1990 during National Fire Prevention Week.

The primary goal of PROJECT GET ALARMED is to educate parents and caregivers about the importance of having properly functioning and maintained smoke detectors for the early detection of residential fires as well as having practiced home escape plans. To help achieve this, the Campaign developed an educational slide show for use during presentations to parents, a brochure, print and television public service announcements (PSAs), a fire safety magazine for kids, and two kits, each targeting reporters who write for adult and children's media. PROJECT GET ALARMED attracted extensive media attention, including airing of the PSAs on several networks. In addition, eight national newspapers ran stories on residential fire safety, 11 national magazines featured fulllength articles on the topic, and hundreds of articles, with a circulation of at least 3.7 million, were published.

Since the launch of the program, over 50000 smoke detectors and batteries have been installed in the homes of low-income families with young children. The coalitions have developed innovative ways to distribute smoke detectors and replacement batteries including projects with Women, Infants and Children programs, Head Start, home health care agencies, fire departments, childbirth education classes, social service agencies, and residents of highrisk areas, such as public housing and mobile homes. In addition, the Campaign has endeavored to maintain smoke detectors in good working order through coalitions' followup distribution of batteries to low-income families and by asking local utility companies to include a 'bill stuffer' (a leaflet in envelopes with the billing) that encourages parents to test and maintain smoke detectors.

Through PROJECT GET ALARMED, the Campaign has also made progress in the legislative arena. SAFE KIDS is continuing to push for smoke detector legislation in the nine states lacking such laws. In addition, the Campaign has successfully advocated for passage of the Federal Fire Safety Act, which mandates smoke detectors in all federal housing; developed model smoke detector legislation for coalitions to use in pushing for state and local laws; and worked with the Children's Sleepwear Coalition to oppose changes in the current federal standards for children's sleepwear flammability.

\section{National SAFE KIDS Week}

Each year during National SAFE KIDS Week in May, coalitions conduct highly visible activities in their communities (for example, safety fairs, bicycle rodeos, child safety seat checks) that complement intensive media and public policy outreach at the national level.

National SAFE KIDS Week '94 brought unprecedented success to the National SAFE KIDS Campaign on three major fronts-coalition activities, media coverage, and public policy. The Campaign brought together major organizations, retailers, and volunteers to engage in injury prevention nationwide. A total of 150 state and local coalitions participated in over 900 events which involved roughly 5000 volunteers and reached approximately 304000 people. Coalitions targeted those most in need by distributing or selling at a discount over $\mathbf{2 0} 000$ safety devices, 
including 15000 bicycle helmets, 4900 smoke detectors, and 1100 child safety seats.

Media coverage reached new heights, bringing more national visibility to the Campaign than ever before. A special episode of 'Rescue 911' on CBS, sponsored by Johnson \& Johnson, focusing on SAFE KIDS risk areas, reached almost 10 million viewers; over 600 stories on $300 \mathrm{TV}$ stations reached more than 71 million viewers; and more than 1500 placements were made in newspapers and magazines (total circulation 121 million). On 9 May, a four page SAFE KIDS supplement to $U S A$ Today had a circulation of 1.9 million. Coalitions and retailers also distributed 800000 reprints.

Legislative activities on Capitol Hill and in state legislatures raised the Campaign's presence, prestige and ability to shape public policy. The SAFE KIDS Summit brought 102 children from all 50 states and the District of Columbia to Washington to impress upon Congress and the public the need to include childhood injury prevention in the health care reform debate. Activities for the children included: a news conference with $C$ Everett Koop, MD, and Senator Christopher Dodd, Chairman of the United States Senate Subcommittee on Children, Family, Drugs, and Alcoholism; 100 congressional visits to personally bring the message that childhood injury prevention saves lives as well as health care dollars; and testifying at a Senate subcommittee hearing chaired by Senator Dodd focusing on the health costs associated with preventable childhood injuries. The success of the Summit came with Senator Dodd's support of a special childhood injury prevention amendment that was included in the health care reform bills of Senators Kennedy and Mitchell as well as other public health legislation. The success of National SAFE KIDS Week '94 is a testament to a well coordinated partnership between the public and private sectors.

\section{Research}

The Campaign has conducted both process and impact evaluation at the national and grassroots levels. For example, the Campaign funded 10 coalitions to determine the proportion of working smoke detectors in low-income homes six months after they had been installed by SAFE KIDS volunteers compared with the proportion of working smoke detectors in other homes in the neighborhood (data forthcoming). Further, in 1987, 1992, and 1995, the Campaign commissioned national surveys of parental knowledge, attitudes, and behaviors concerning childhood injury and has documented trends over time. In addition, individual coalitions have conducted bicycle helmet and child safety seat observational surveys, and measured, before and after the surveys, the effectiveness of educational presentations, and statewide attitudinal surveys of parents and caregivers.

\section{Conclusion}

Since the Campaign's inception, and working in partnership with several organizations and individuals, overall unintentional injury deaths in the United States have declined more than $17 \%$. The Campaign was honored by its peers in 1989 with the Public Relations Society of America's Silver Anvil award for 'excellence in public service', and in 1991, with the National Head Injury Foundation's Silvio O Conte award for 'improving quality of life and promoting prevention'. In 1993, the Campaign received a Centers for Disease Control and Prevention award as a model prevention program at the Second World Conference on Injury Control. Working together, we can ensure that 'SAFE KIDS are no accident! ®'.

For additional information concerning the National SAFE KIDS Campaign or to receive a free catalog of resource materials, please write to 111 Michigan Avenue, NW, Washing ton, DC 20010-2970, USA. 